\title{
Experimental Study of the Effectiveness of a Combined Closure of the End Gate Pipeline Valve
}

\author{
Henrikh H. Herasymov ${ }^{1}$, Ievgenii G. Gerasimov ${ }^{2}$, Sergiy Y. Ivanov $^{1}$, \\ Oleg L. Pinchuk ${ }^{3}$ \\ ${ }^{1}$ Department of Water Power Engineering, Heat Power Engineering and Hydraulic Machines, National \\ University of Water and Environmental Engineering, Rivne, vul. Soborna, 11; ${ }^{2}$ Research Department, \\ National University of Water and Environmental Engineering, Rivne, vul. Soborna, 11, Corresponding \\ author, e-mail: e.g.gerasimov@ nuwm.edu.ua; ${ }^{3}$ Department of Computer Science in Water Engineering, \\ National University of Water and Environmental Engineering, Rivne, vul. Soborna, 11
}

(Received February 20, 2019; revised June 19, 2019)

\begin{abstract}
One of the ways to ensure a reliable operation of irrigation systems is to protect them from water hammer (hydraulic shock) damage that occurs when starting or stopping a pumping station. This can be achieved by creating conditions in which a water hammer will not occur in the pressure pipeline as a result of closing the end gate valve (EGV). The aim of the present study was to investigate processes occurring in the pipeline during a linear closure of the EGV, during a closure with one break point and during an intermittent closure, as well as to verify the effectiveness of a combined end gate valve closure of the pipeline. Based on experimental data and calculations, the article recommends a linear closure of the EGV with one break point.
\end{abstract}

Key words: Valve closure modes, experimental installation, valve control device, results of experimental studies

\section{Introduction}

In reconstructing and modernizing closed irrigation systems (CIS), it is necessary to ensure their reliable and efficient operation during different types of operating mode. In particular, it is important to protect CIS from water hammer (WH) caused by starting or stopping a sprinkler irrigation system or a pumping station. One of the methods of reducing the water hammer effect is a combined closure of the end gate pipeline valve. However, the practical implementation of this method in CIS is difficult due to the long closing time. Therefore, the practical execution of a combined closure of the

(C) 2019 Institute of Hydro-Engineering of the Polish Academy of Sciences. This is an open access article licensed under the Creative Commons Attribution-NonCommercial-NoDerivs License (http://creativecommons.org/licenses/by-nc-nd/3.0/). 
end gate pipeline valve needs to be considered from experimental and mathematical perspectives.

\section{Formulation of the Problem}

Despite numerous scientific studies and new developments in production, the social and economic crisis in Ukraine over the last 10 to 15 years has been a significant obstacle to hydrotechnical amelioration (Herasymov 2007). The pipeline fittings used in the existing CIS and drainage facilities are not designed to prevent the occurrence of water hammer in CIS pipelines, but rather to eliminate the already existing waves of elevated pressure in the pipeline network (Herasymov 2007, Design of Closed Irrigation Systems 1986). Such pipeline fittings do not ensure a high reliability and efficient operation of CIS pipelines. Moreover, sterile spills that occur through various bursting discs, discharging valves and water hammer blocking devices have a negative impact on energy conservation. Under such conditions, accidents in pipeline networks result in frequent downtimes of CIS, which in turn disrupt crop irrigation and negatively affect agricultural yields.

\section{Experimental Installation}

The most rational way of protecting CIS pipelines from water hammer is to prevent high-pressure waves in the pipeline network. This can be achieved that by using the "perfect" principle of the closure of the end gate valve (EGV). However, this closure mode is a regime in which pressure in the pipeline remains constant until the gate is completely closed. Nonetheless, the velocity defect law for such an EGV closure is rather complicated and virtually impossible to implement (Kilimnik 1971). That is why the "perfect" closure mode should be understood as a conditional mode, which, in its practical application, gives us a somewhat different hydrodynamic picture. Furthermore, it leads to a slightly increased pressure in the final pipeline over the ordinary working, with a complete EGV closure. Therefore, the main task is to define and generalize the "perfect" mode of EGV closure which would best approximate the "ideal" one and to develop appropriate shut-off valves, for which shut-off device would reproduce the given mode upon closure.

In particular, our task at this stage is to verify the effectiveness of a combined EGV closure experimentally. We will consider the following options for EGV closure:

1. EGV closure with one break point (Herasymov, Ivanov 2005).

2. Stepped EGV closure (Herasymov, Ivanov 2006).

We conducted our tests in an experimental installation for water hammer investigation in the laboratory of the Department of Water Power Engineering and Hydraulic Machines. The experimental installation (see Fig. 1) consists of an underwater pressure pipeline (1) shut off by a gate valve (2), a pressure tank (3) designed to create constant pressure at the beginning of the closed pipeline network (4), and a waste pipeline (5). The gate valve (2) regulates the flow rate in the installation so that there 


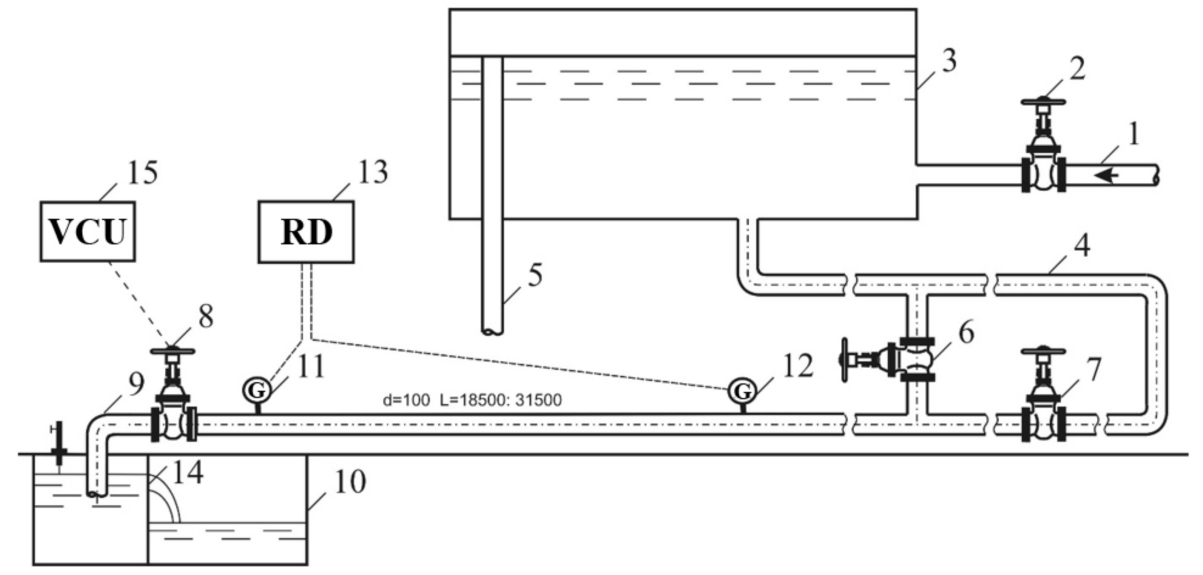

Fig. 1. Experimental installation diagram.

1 - underwater pressure pipeline; 2, 6, 7 - gate valves; 3 - pressure tank; 4 - steel pipeline with a diameter of $100 \mathrm{~mm}$ and a length of $31.5 \mathrm{~m} ; 5$ - waste pipeline; 8 - gate valve with a controlled drive; 9 - service pipeline; 10 - by-pass tank; 11, 12 - pressure sensors; 13 recording device; 14 - triangular weir gauge; 15 - valve control unit

is no significant overflow in the pressure tank (3) with the maximum flow rate of the closed pipeline and so that there is a constant water level at the same time. The closed pipeline network (4) is a pressure pipeline with a short branch and a long branch, which are shut off by gate valves 6 and 7, respectively. Since the present experimental studies involved only the long section of the pipeline, gate valve 6 was closed and gate valve 7 was open. The diameter of the experimental steel pipeline is $100 \mathrm{~mm}$, and the working length of the pipeline is $31.5 \mathrm{~m}$. At the end of the closed pipeline network there is an end gate valve (hydrant) with a controlled drive (8), which helps to study different closure modes. The water discharge passes through a service pipeline (9) under the level of a by-pass tank (10), which ensures a constant static pressure in the experimental installation and its steady operation. Pressure sensors (11 and 12) are installed at pressure gauges with strain-gauge sensors to determine the pressure head near the valve and at the end of the pressure pipeline (4). These sensors are connected to a recording device (an electromagnetic oscillograph) (13), which periodically records the pressure at the control points and the position of the lock of the end gate valve with a controlled drive (the relative gate valve closure). The flow in the closed pipeline network is measured by a triangular weir gauge (14) (Kurganov, Fedorov 1986) installed on the sidewall of the by-pass tank (10). The water level in the triangular weir gauge is measured by a point gauge. The end gate valve with the controlled drive (8) closes according to the closure mode set by a valve control unit (VCU) (15).

In our experiments we used a 12-channel electromagnetic oscillograph (K12-22 1978) as a recording device for the processes investigated, which had previously been 
converted into electrical values. At the same time, we used the valve control unit, which closed the EGV in a predetermined way, as an automatic control device for the actuating element.

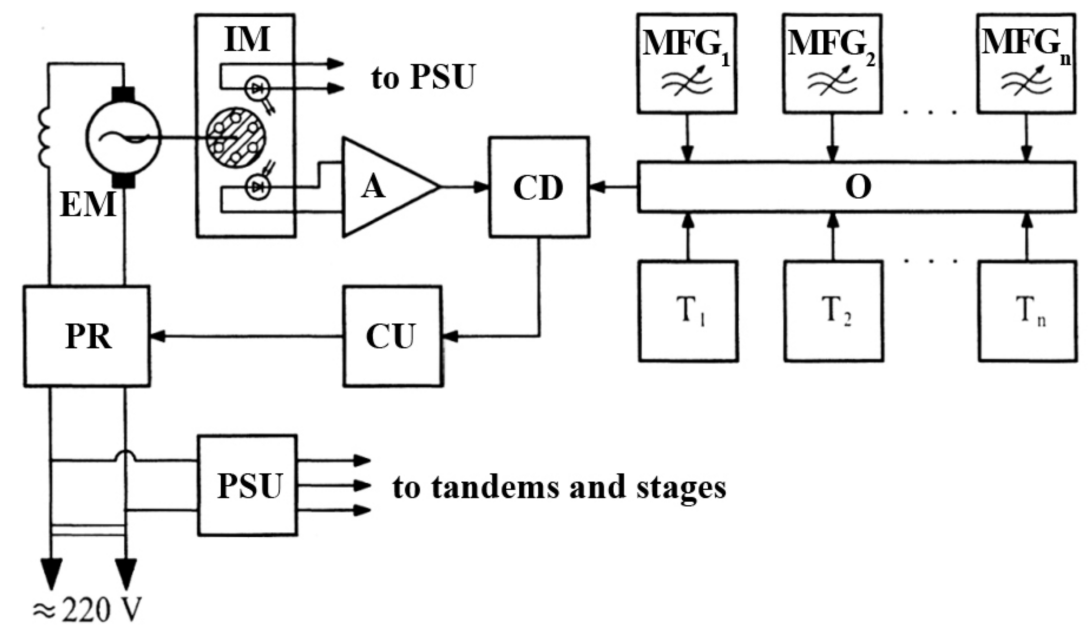

Fig. 2. Block diagram of the valve control unit.

$\mathrm{MFG}_{1} \ldots \mathrm{MFG}_{n}$ - master frequency generators; $\mathrm{T}_{1} \ldots \mathrm{T}_{n}$ - timers; $\mathrm{O}$ - oscillator; IM - impulse meter; A - amplifier; CD - comparison device; $\mathrm{CU}$ - control unit; $\mathrm{PR}$ - power regulator; PSU - power supply unit; EM - electric motor

Fig. 2 shows a block diagram of the valve control unit, which works as follows. The required rotation frequencies of the header electric motor (EGV closure velocity) and the duration of each of these closings is assigned by master frequency generators $\left(\mathrm{MFG}_{1} \ldots \mathrm{MFG}_{n}\right)$. An oscillator $(\mathrm{O})$ sequentially switches the master frequency generators on and off according to intervals set for timers and sends a signal to a comparison device (CD). This comparison device also receives an amplified signal from an amplifier (A), which is read from an impulse meter (IM). The impulse meter consists of a photopair (light diodes and photodiodes) and a perforated disk that is mechanically connected to the rotor of an electric motor. When rotating, the perforated disk modulates the luminous flux entering the photodiode (Piontak, Skliar 1985). The frequency of the alternating current flowing through the photodiode is proportional to the rotation frequency of the electric motor. The signal read from the impulse meter serves as a feedback, which ensures proper tracking of the frequency set by the master frequency generators for the electric motor. When the signals are compared by the comparing device, a deviation signal is formed and sent to the control unit (CU) of the power regulator (PR). The power regulator increases or decreases the power of the electric motor depending on the sign of the deviation signal, which ensures that the motor tracks the set rotation frequency. A power supply unit (PSU) is used to power all tandems and stages of the valve control unit. 
Table 1. Results of experiments verifying the effectiveness of a combined EGV closure and results of calculations based on experimental data

\begin{tabular}{|c|c|c|c|c|c|c|c|c|c|c|c|c|}
\hline \multirow[b]{3}{*}{ 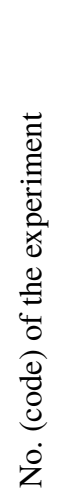 } & \multirow[b]{3}{*}{$\begin{array}{l}\infty \\
\vec{a} \\
\dot{\alpha} \\
\dot{0} \\
\frac{0}{I}\end{array}$} & \multicolumn{5}{|c|}{ Mode of EGV closure } & \multirow[b]{3}{*}{ 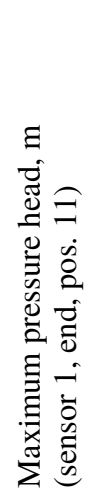 } & \multirow[b]{3}{*}{ 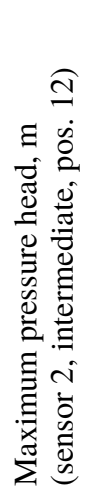 } & \multirow[b]{3}{*}{ 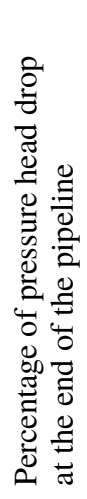 } & \multirow{3}{*}{ 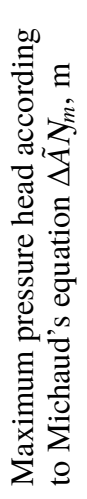 } & \multirow{3}{*}{ 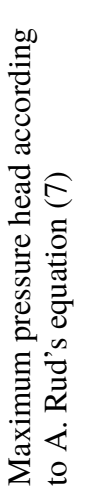 } & \multirow[b]{3}{*}{ 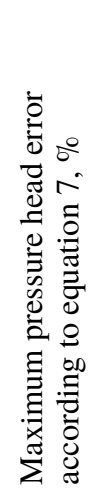 } \\
\hline & & \multirow[b]{2}{*}{ 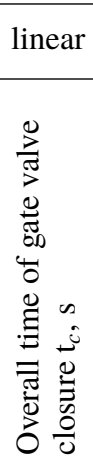 } & \multicolumn{2}{|c|}{$\begin{array}{c}\text { with a break } \\
\text { point }\end{array}$} & \multicolumn{2}{|c|}{ stepped } & & & & & & \\
\hline & & & 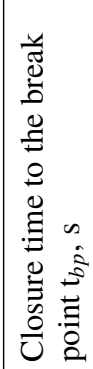 & 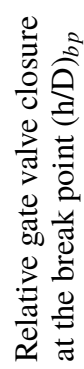 & 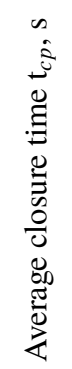 & 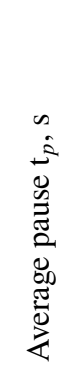 & & & & & & \\
\hline \multicolumn{13}{|c|}{ Linear EGV closure } \\
\hline $1 / 1$ & 7.43 & 6.6 & - & - & - & - & 7.649 & 5.500 & 13.0 & 1.066 & 8.19 & -7.07 \\
\hline $2 / 1$ & 7.43 & 7.0 & - & - & - & - & 7.267 & 5.300 & 17.4 & 1.005 & 7.85 & -8.02 \\
\hline $1 / 2$ & 7.43 & 6.0 & - & - & - & - & 8.796 & 4.392 & 0 & 1.172 & 8.82 & -2.73 \\
\hline $3 / 2$ & 7.43 & 6.4 & - & - & - & - & 7.553 & 4.176 & 14.1 & 1.099 & 8.39 & -16.77 \\
\hline $11 / 2$ & 7.43 & 9.6 & - & - & - & - & 5.164 & 3.384 & 41.3 & 0.733 & 6.57 & -27.07 \\
\hline $12 / 2$ & 7.43 & 10.8 & - & - & - & - & 4.687 & 3.240 & 46.7 & 0.650 & 6.3 & -34.4 \\
\hline \multicolumn{13}{|c|}{ EGV closure with one break point } \\
\hline $5 / 2$ & 7.43 & 5.6 & 3.2 & 0.36 & - & - & 8.796 & 4.680 & 0.0 & 1.056 & 8.14 & +7.46 \\
\hline $6 / 2$ & 7.43 & 6.8 & 3.6 & 0.29 & - & - & 5.451 & 3.384 & 38.0 & 0.638 & 6.86 & -14.84 \\
\hline $7 / 2$ & 7.43 & 8.8 & 3.0 & 0.43 & - & - & 4.782 & 3.168 & 45.6 & 0.521 & 6.01 & -12.28 \\
\hline $8 / 2$ & 7.43 & 7.2 & 3.4 & 0.36 & - & - & 5.069 & 3.312 & 42.4 & 0.670 & 6.36 & -25.48 \\
\hline $9 / 2$ & 7.43 & 7.8 & 3.6 & 0.29 & - & - & 4.113 & 2.592 & 53.2 & 0.485 & 5.96 & -36.43 \\
\hline $10 / 2$ & 7.43 & 6.6 & 4.0 & 0.17 & - & - & 4.209 & 2.952 & 52.1 & 0.459 & 5.93 & -40.88 \\
\hline \multicolumn{13}{|c|}{ Stepped EGV closure } \\
\hline $15 / 1$ & 7.43 & 13.0 & - & - & 6.50 & 6.50 & 6.407 & 4.800 & 27.2 & - & - & - \\
\hline $16 / 1$ & 7.43 & 18.0 & - & - & 1.20 & 1.20 & 4.400 & 3.600 & 50.0 & - & - & - \\
\hline $18 / 1$ & 7.43 & 16.4 & - & - & 0.71 & 0.71 & 4.591 & 3.500 & 47.8 & - & - & - \\
\hline $19 / 1$ & 7.43 & 14.0 & - & - & 0.61 & 0.61 & 5.260 & 4.000 & 40.2 & - & - & - \\
\hline $20 / 1$ & 7.43 & 10.0 & - & - & 0.44 & 0.44 & 4.687 & 3.600 & 46.7 & - & - & - \\
\hline $13 / 2$ & 7.43 & 9.6 & - & - & 1.07 & 1.07 & 7.649 & 4.392 & 13.0 & - & - & - \\
\hline $14 / 2$ & 7.43 & 10.0 & - & - & 1.11 & 1.11 & 8.509 & 4.752 & 3.3 & - & - & - \\
\hline
\end{tabular}

\section{Results of Experimental Studies}

Data obtained by the experiments verifying the effectiveness of a combined EGV closure are presented in Table 1.

One of the most important parameters of the valve closing process is the relative gate valve closure at the break point $(h / D)$, which represents the degree of valve opening. 
After a comparative analysis of data obtained under the three different modes of EGV closure, it is possible to formulate the following preliminary conclusions about their effectiveness and appropriateness:

1. In order to compare the values of the water hammer (hydraulic shock) pressure head, we conducted experiments with a linear closure in which the maximum hammer pressure head in the pipeline in front of the closing gate valve was obtained. For purposes of comparison, was chose the worst case, that is, experiment $1 / 2$. Fig. 3a depicts pressure head changes for a linear closure. In this case, the maximum shock pressure head is $H_{\max , l i n .}=8.796 \mathrm{~m}$, with the minimum from the total duration of linear closure $t_{c}=6 \mathrm{sec}$.

2. We also performed experiments involving EGV closure with one break point for various values of relative closure $(h / D)$ and relative time $\left(t_{b p} / t_{c}\right)$. The results of these experiments revealed that EGV closure with one break point (experiment 9/2) when $h / D=0.29$ and $t_{b p} / t_{c}=0.46$ (see Fig. 3b) decreased water hammer compared to the linear closure by $53.2 \%\left(\mathrm{H}_{\text {max,b.p. }}=4.113 \mathrm{~m}\right)$. Furthermore, it should be noted that EGV closure with one break point, $h / D=0.17$ and $t_{b p} / t_{c}=$ 0.61 (experiment 10/2, see Fig. 3c) created an almost identical, somewhat larger, hammer pressure head $\mathrm{H}_{\text {max,b.p. }}=4.209 \mathrm{~m}$. Since these pressure heads are almost identical, the modes of EGV closure with one break point should be considered effective, as confirmed experimentally.

3. Likewise, we also carried out experiments with stepped EGV closure. This closure mode is characterised by the number of stops $(Z)$. It was conditionally assumed (with an insignificant deviation percentage) that $t_{\text {closed }}=t_{\text {stop }}$. According to the results of the experiments, stepped EGV closure (experiment 16/1) with the number of stops $Z=7$ (see Fig. 3d) reduced water hammer by $50.0 \%$ compared to a linear closure $\left(H_{\text {max,step. }}=4.400 \mathrm{~m}\right)$. Thus, this closure mode should also be considered effective, which was confirmed experimentally.

Let us analyse the results of experimental studies with the view to calculating the maximum hammer pressure head during end gate valve closure. In order to compare the results of all tests performed with a constant water flow $Q=0.00743 \mathrm{~m}^{3} / \mathrm{s}$, let us find the average water velocity in the pipeline of the experimental installation having the diameter $D=0.1 \mathrm{~m}$ :

$$
\begin{gathered}
v=\frac{Q}{f}=\frac{4 Q}{\pi D^{2}}, \\
v=\frac{4 \cdot 0.00743}{3.14 \cdot 0.1^{2}}=0.946 \mathrm{~m} / \mathrm{s} .
\end{gathered}
$$

According to (Herasymov 2007, Table 5, p. 365), the kinematic viscosity coefficient for water at a temperature $t=20^{\circ} \mathrm{C}$ is $v=1.006 \cdot 10^{-6} \mathrm{~m}^{2} / \mathrm{s}$. Then the Reynolds number $(R e)$ is

$$
\operatorname{Re}=\frac{v D}{v}
$$



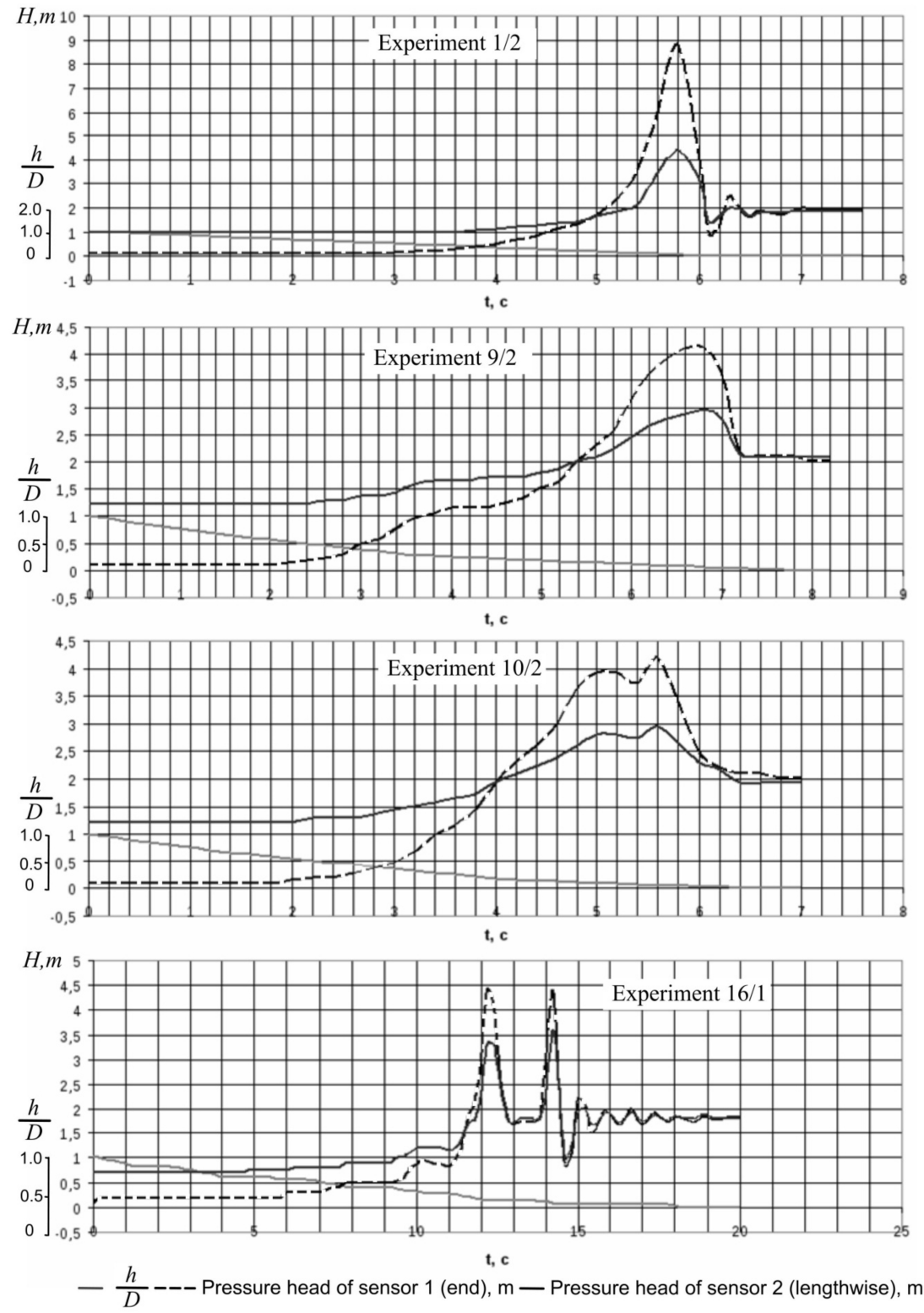

Fig. 3. Pressure head changes for different modes of EGV closure: a) linear; b, c) with a break point; d) stepped

$$
R e=\frac{0.946 \cdot 0.1}{1.006 \cdot 10^{-6}}=94000>10000
$$

which indicates the turbulent flow of water. According to the original oscillogram of experiment $1 / 2$, the time interval between pressure peaks was $\Delta t=0.03 \mathrm{~s}$, so the celer- 
ity of the pressure wave was $a=L_{1} / \Delta t=11.5 / 0.03=380 \mathrm{~m} / \mathrm{s}$. hen, for the pipeline with a length of $L=31.5 \mathrm{~m}$, the water hammer phase is determined as follows:

$$
\begin{gathered}
t_{p h}=\frac{2 L}{a}, \\
t_{p h}=\frac{2 \cdot 31.5}{380}=0.192 \mathrm{~s} .
\end{gathered}
$$

With regard to the data in Table 1, it should be emphasized that the realized at the experiments times of closing the gate valve significantly exceed the hydraulic shock phase, which explains indirect hydraulic shocks noted in the experiments. In the case of direct hydraulic shock, the maximum hammer pressure head is determined according to the equation of M. Y. Zhukovsky (Kurganov, Fedorov 1986, p. 110):

$$
H_{\max }=\frac{a v}{g},
$$

where $g$ is gravitational acceleration, $g=9.81 \mathrm{~m} / \mathrm{s}^{2}$.

$$
H_{\max }=\frac{380 \cdot 0.946}{9.81}=36.64 \mathrm{~m},
$$

which is much higher than shock pressure heads obtained experimentally with indirect hydraulic shocks. This confirms the effectiveness of increasing the gate valve closure time relative to the water hammer phase to reduce the shock pressure head.

However, in the case of a combined gate valve closure, what has a significant impact on reducing hammer pressure head is not the gate valve closure time $t_{c}$, but rather the rate of change in the relative gate valve closure in the final part of that period, namely $d(h / D) / d t$. Using the values measured and the finite differences between them, we obtained the following equations:

$\Delta(h / D) / \Delta t=1 / t_{c}$ for a linear gate valve closure, and

$\Delta(h / D) / \Delta t=(h / D)_{h p} / t_{c}-t_{b p}$ for a combined gate valve closure.

Using the similarity of triangles, it is possible to determine the time $t_{c l}$ of a linear gate valve closure which is equivalent to a combined closure from the value of the maximum shock pressure head:

$$
t_{c l}=\frac{t_{c}-t_{b p}}{\left(\frac{h}{D}\right)_{b p}} .
$$

The maximum hammer pressure head with an indirect hydraulic shock and a linear change in flow velocity is typically determined using Michaud's equation (Herasymov 2007, p. 107; Kodura 2016):

$$
\Delta H_{m}=\frac{2 v L}{g t_{c}}=\frac{a v}{g} \cdot \frac{t_{p h}}{t_{c}}
$$


Let us consider the methodology for calculating an indirect hydraulic shock developed by A. Rud (1976) for end gate valve closure in closed irrigation networks (Rud 1976). The equation takes the following form:

$$
\Delta H=m \frac{a v}{g}\left[0.87 \cdot \exp \left(-0.076 \cdot \frac{t_{c l} a}{2 L}\right)+0.16\right],
$$

where $m$ is a coefficient describing conditions in a closed pipeline network. For a network with Fregat sprinkler machines $m=0.92 \ldots 1$; for a single operation of a sprinkler machine and the presence of dead ends $m=1.24$; without dead ends $m=1$; accepted it as $m=1$.

The results of calculations using these formulas are summarised in Table 1 and shown in Fig. 4.

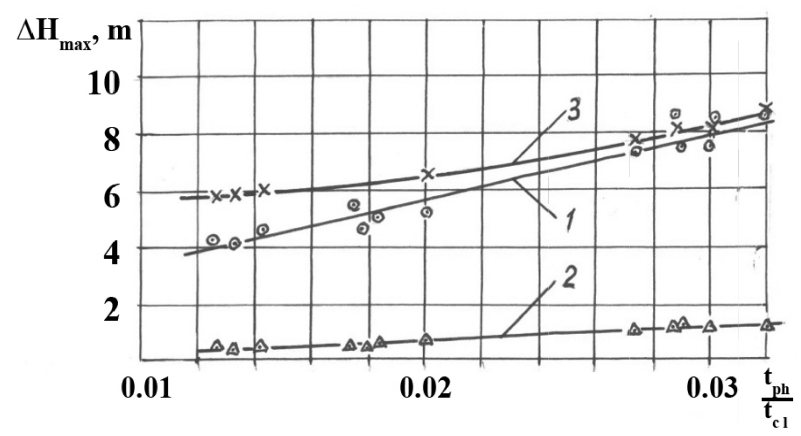

Fig. 4. Dependence of the maximum pressure head on the time of linear gate valve closure $\Delta H=f\left(t_{p h} / t_{c l}\right): 1$ - according to experimental data; 2 - according to Michaud's equation; 3 according to A. Rud's equation

According to calculations (see Table 1), the maximum pressure head from Michaud's equation is just a small fraction of the experimental data value, which shows that Michaud's equation is not suitable under our experimental conditions.

As shown by data in Table 1, the maximum shock pressure from A. Rud's equation (Rud 1976) is slightly higher than the experimental data, thus, the calculations envisage a certain margin.

It is known that the active throttling of the flow by a gate valve during closure occurs under the values of relative closure $(h / D)=0.1 \ldots 0.2$. In addition, the results of the mathematical modelling of end gate valve closure (Herasymov, Ivanov 2005) show that the most suitable option is a combined linear closure with one break point when $t_{b p}=0.25 t_{c}$ and $(h / D)_{b p}=0.1$.

\section{Conclusions}

In view of the above, it is possible to recommend a combined linear gate valve closure with one break point, whose coordinates are within the 1-2-3-4 rectangle with $t_{b p}=$ 


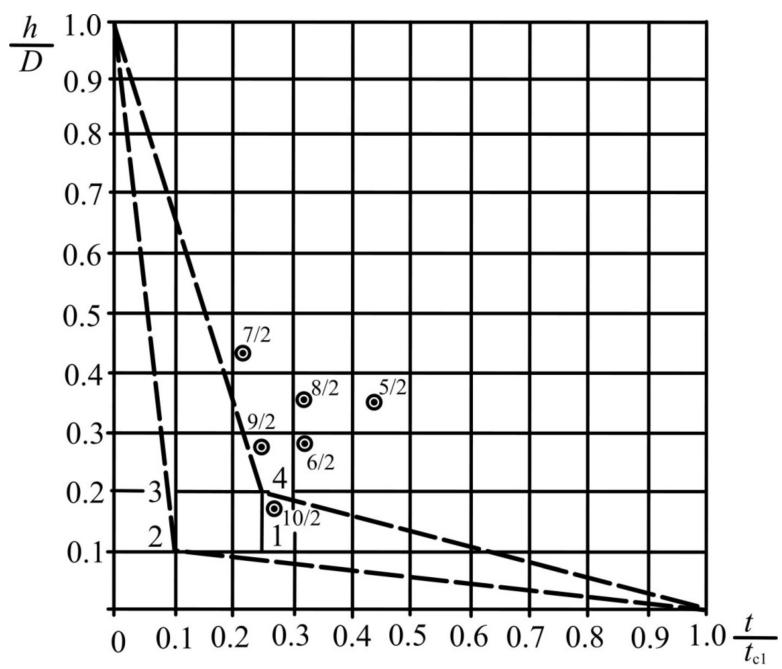

Fig. 5. Recommended charts for changing the relative opening of the end gate valve of a pipeline: break points of valve closure in the experiments are marked by points; the dashed line on the left represents the results of mathematical modelling (Herasymov, Ivanov 2005)

$(0.1 \ldots 0.25) t_{c}$ and $(h / D)=0.1 \ldots 0.2$ (see Fig. 5). We also suggest that all gate valve closure charts be located within the geometric shape represented by the dashed lines.

The results of experimental and mathematical research indicate that the largest increase in the pressure of water hammer occurred towards the end of valve closure, from $(h / D)=0.1 \ldots 0.2$ to the full closing of the valve.

In conclusion, our experiments and calculations confirm the practical value of a combined closure of the end gate pipeline valve that can be performed by two operating periods: fast closing of the valve to a relative closure $(h / D)=0.1 \ldots 0.2$ and then by closing it slowly to reduce the water hammer effect.

\section{References}

12-Channel Electromagnetic Oscillograph K12-22 (1978) Technical Specification and Operation Manual, ZPE.407.020 TO, 71 p. (in Russian).

Design of Closed Irrigation Systems. Pipes, fittings, equipment (1986) Ed. V. Dikarevskii, Moscow, Agropromizdat, p. 192-234 (in Russian).

Herasymov H. (2007) Designing Automated Pumping Stations: Textbook [online], Rivne: NUWEE, 552 p. Available at: http://ep3.nuwm.edu.ua/id/eprint/2265 [Accessed 7 Jan. 2019] (in Ukrainian).

Herasymov H., Ivanov S. (2005) Combined Closure of Pipeline End Gate Valve, Bulletin of NUWEE, 4 (32), Rivne: NUWEE, 111-118. (in Ukrainian).

Herasymov H., Ivanov S. (2006) Rational Methods of Irrigation Pipeline End Gate Valve Closure, Reclamation and Water Supply. 93-94, Kyiv, Agrarian Science, 231-235 (in Ukrainian).

Kilimnik V. (1971) Some Issues of Unifying Means of Protection of Hydraulic Systems Against Water Hammer, Exploitation of Mineral Deposits, 24, Kyiv, Tekhnika, 50-53 (in Russian). 
Kodura A. (2016) An Analysis of the Impact of Valve Closure Time on the Course of Water Hammer, Archives of Hydro-Engineering and Environmental Mechanics, 63.10.1515/heem-2016-0003.

Kurganov A., Fedorov N. (1986) Hydraulic Calculations of Water Supply and Sewerage Systems. Guidebook, Leningrad, Stroyizdat, pp. 205-206 (in Russian).

Piontak B., Skliar E. (1985) Rotational Velocity Sensor Radio, 11, 32-33 (in Russian).

Rud A. (1976) Wave Processes in Irrigation Pipelines with "Frigate" Irrigation Sprinklers, Hydraulics and Hydrotechnics: Interuniversity Collected Volume Papers, 166, Kishineu: KAgl, 64-68 (in Russian). 